\title{
Association between the number and size of intrapulmonary lymph nodes and chronic obstructive pulmonary disease severity
}

\author{
Anton Schreuder ${ }^{\text {Corresp., }}{ }^{1}$, Colin Jacobs ${ }^{1,2}{ }$, Ernst T Scholten ${ }^{1}$, Mathias Prokop ${ }^{1}$, Bram van Ginneken ${ }^{1,2}$, David A \\ Lynch $^{3}$, Cornelia M Schaefer-Prokop ${ }^{1,4}$ \\ 1 \\ ${ }^{1}$ Department of Radiology and Nuclear Medicine, Radboudumc, Nijmegen, the Netherlands \\ Fraunhofer MEVIS, Bremen, Germany \\ 3 Department of Radiology, National Jewish Medical and Research Center, Denver, Colorado, United States of America \\ 4 Department of Radiology, Meander Medisch Centrum, Amersfoort, the Netherlands \\ Corresponding Author: Anton Schreuder \\ Email address: antoniusschreuder@gmail.com
}

Purpose: One of the main pathophysiological mechanisms of chronic obstructive pulmonary disease is inflammation, which has been associated with lymphadenopathy. Intrapulmonary lymph nodes can be identified on $\mathrm{CT}$ as perifissural nodules (PFN). We investigated the association between the number and size of PFNs and measures of COPD severity.

Materials and Methods: $\mathrm{CT}$ images were obtained from COPDGene. 50 subjects were randomly selected per GOLD stage (0 to 4), GOLD-unclassified, and never-smoker groups and allocated to either "Healthy," "Mild," or "Moderate/severe" groups. 26/350 (7.4\%) subjects had missing images and were excluded. Supported by computer-aided detection, a trained researcher prelocated non-calcified opacities larger than $3 \mathrm{~mm}$ in diameter. Included lung opacities were classified independently by two radiologists as either "PFN," "not a PFN," "calcified," or "not a nodule"; disagreements were arbitrated by a third radiologist. Ordinal logistic regression was performed as the main statistical tests.

Results: 592 opacities were included in the observer study. 163/592 classifications (27.5\%) required arbitration. 17/592 opacities (2.9\%) were excluded from the analysis because they were not considered nodular, were calcified, or all three radiologists disagreed. 366/575 accepted nodules (63.7\%) were considered PFNs. A maximum of 10 PFNs were found in one image; 154/324 (47.5\%) contained no PFNs. The number of PFNs per subject did not differ between COPD severity groups $(p=0.50)$. PFN short-axis diameter could significantly distinguish between the Mild and Moderate/severe groups, but not between the Healthy and Mild groups $(p=0.021)$.

Conclusions: There is no relationship between PFN count and COPD severity. There may be a weak trend of larger intrapulmonary lymph nodes among patients with more advanced stages of COPD. 
4 Anton Schreuder ${ }^{1}$; Colin Jacobs ${ }^{1,2}$; Ernst T Scholten ${ }^{1}$; Mathias Prokop ${ }^{1}$; Bram van Ginneken ${ }^{1,2}$;

5 David A Lynch ${ }^{3}$; Cornelia M Schaefer-Prokop ${ }^{1,4}$; COPDGene investigators

6

$7 \quad{ }^{1}$ Department of Radiology and Nuclear Medicine, Radboudumc, Nijmegen, the Netherlands

$8 \quad 2$ Fraunhofer MEVIS, Bremen, Germany

$9{ }^{3}$ Department of Radiology, National Jewish Medical and Research Center, Denver, CO, USA

$10{ }^{4}$ Department of Radiology, Meander Medisch Centrum, Amersfoort, the Netherlands

12 Corresponding author

13 Anton Schreuder ${ }^{1}$

14 Geert Grooteplein Zuid 10, 6525 GA, Nijmegen, the Netherlands

15 E-mail: antoniusschreuder@gmail.com

17 This article has an online data supplement

19 Short title: Intralung lymph nodes and COPD severity 


\section{List of abbreviations}

$21 \mathrm{COPD}=$ chronic obstructive pulmonary disease

22 GOLD $=$ Global Initiative for Chronic Obstructive Lung Disease

23 FEV1 = forced expiratory volume in 1 second

$24 \quad \mathrm{FVC}=$ forced vital capacity

$25 \mathrm{mMRC}=$ Modified Medical Research Council

$26 \quad \mathrm{PFN}=$ perifissural nodule

27 Pi10 $=$ bronchial wall thickness

28 PRISm $=$ preserved ratio impaired spirometry

\section{List of keywords}

31 chronic obstructive pulmonary disease; lymph node; pulmonary nodule; prevalence; observer 32 variation

\section{Funding support:}

35 The COPDGene ${ }^{\circledR}$ project was supported by Award Number U01 HL089897 and Award Number

36 U01 HL089856 from the National Heart, Lung, and Blood Institute. COPDGene $\AA$ is also

37 supported by the COPD Foundation through contributions made to an Industry Advisory Board

38 comprised of AstraZeneca, Boehringer Ingelheim, GlaxoSmithKline, Novartis, Pfizer, Siemens

39 and Sunovion. 


\section{Abstract}

43 Purpose: One of the main pathophysiological mechanisms of chronic obstructive pulmonary

44 disease is inflammation, which has been associated with lymphadenopathy. Intrapulmonary

45 lymph nodes can be identified on CT as perifissural nodules (PFN). We investigated the

46 association between the number and size of PFNs and measures of COPD severity.

47 Materials and Methods: CT images were obtained from COPDGene. 50 subjects were randomly

48 selected per GOLD stage (0 to 4), GOLD-unclassified, and never-smoker groups and allocated to

49 either "Healthy," "Mild," or "Moderate/severe" groups. 26/350 (7.4\%) subjects had missing

50 images and were excluded. Supported by computer-aided detection, a trained researcher

51 prelocated non-calcified opacities larger than $3 \mathrm{~mm}$ in diameter. Included lung opacities were

52 classified independently by two radiologists as either "PFN," "not a PFN," "calcified," or "not a

53 nodule"; disagreements were arbitrated by a third radiologist. Ordinal logistic regression was

54 performed as the main statistical tests.

55 Results: 592 opacities were included in the observer study. 163/592 classifications (27.5\%)

56 required arbitration. 17/592 opacities (2.9\%) were excluded from the analysis because they were

57 not considered nodular, were calcified, or all three radiologists disagreed. 366/575 accepted

58 nodules $(63.7 \%)$ were considered PFNs. A maximum of 10 PFNs were found in one image;

59 154/324 (47.5\%) contained no PFNs. The number of PFNs per subject did not differ between

60 COPD severity groups $(\mathrm{p}=0.50)$. PFN short-axis diameter could significantly distinguish

61 between the Mild and Moderate/severe groups, but not between the Healthy and Mild groups

$62(\mathrm{p}=0.021)$. 
63 Conclusions: There is no relationship between PFN count and COPD severity. There may be a

64 weak trend of larger intrapulmonary lymph nodes among patients with more advanced stages of 65 COPD.

66

67 


\section{Introduction}

Chronic obstructive pulmonary disease (COPD) is an increasingly prevalent disease currently causing about three million deaths per year in 2015 , about $5 \%$ of all deaths world-wide $(1,2)$. The clinical diagnosis of COPD is confirmed using spirometry, defined as a forced expiratory volume in 1 second (FEV1) to forced vital capacity (FVC) ratio of less than 0.7 (3). COPD severity can be further divided into Global Initiative for Chronic Obstructive Lung Disease (GOLD) stages 1 to 4 based on the percentage of the predicted FEV1. More recently, an unclassified GOLD stage better known as "preserved ratio impaired spirometry" (PRISm) is also taken into consideration for cases where FEV1/FVC is above 0.7 but FEV1 is less than $80 \%$ predicted (4).

The pathophysiology of COPD is complex and heterogeneous (5); one of the main mechanisms is immune system-mediated inflammation, which may be associated to the enlargement of mediastinal lymph nodes and development of pulmonary lymphoid follicles (6-9). However, the role of pulmonary lymphatics in COPD remains poorly understood (10); the prevalence and size of intrapulmonary lymph nodes had not yet been studied in this patient group. Typical morphological features of these lymph nodes on CT are a diameter of less than $12 \mathrm{~mm}$, an angular, flat, round, or ovoid shape, solid consistency, sharp margins, extending linear opacities, and a location below the level of the carina within $20 \mathrm{~mm}$ of the pleura (11-18).

In an attempt to accurately identify benign intrapulmonary lymph nodes from malignant pulmonary nodules on $\mathrm{CT}$, some of these typical lymph node features were used to define the perifissural nodule (PFN), a purely radiologic classification (19-22). On the premise that more pulmonary inflammation leads to more identifiable intrapulmonary lymph nodes, we hypothesized that more and larger PFNs would be detected as the COPD severity increases. 


\section{Methods and Materials}

92 CT scans and data

93 CT scans, clinical data, and spirometry outcomes were obtained with approval from the

94 COPDGene study (which was approved by all participating institutional review boards) for the

95 purpose of performing ancillary study number 271 (23). All participants signed the consent form.

96 A Data Access Investigator Certification Form was signed before the data was provided; ethical

97 board approval for our ancillary study was waived. The CT protocols can be found in Appendix

981 of the study design (23). The only subject inclusion criterium was that a baseline and a five-

99 year follow-up CT images were available. We initially calculated a recommended sample size of

10039 per group based on a power analysis to detect an effect size of 0.25 - moderate according to

101 Fritz et al. (24) - with one-way ANOVA of five groups (GOLD stages 0 to 4), where $\alpha=0.05$

102 and power $=0.80$. We performed a pilot study with a sample size of 200 where about $10 \%$ of the

103 scans were missing (results not published). Additional subjects were included to compensate for

104 this. Fifty subjects were randomly selected from each of the following seven groups: smokers in

105 baseline GOLD stages 0 to 4, smokers classified as PRISm, and never-smoking controls (GOLD

$1060)$.

107 Since 2017, the GOLD strategy documents recommended an “ABCD assessment” where COPD

108 patients are further divided into one of four groups (i.e., A, B, C, or D, from low to high risk)

109 depending on symptoms and exacerbation frequency and severity (25). Each individuals'

110 category was determined as a parameter for COPD symptom severity. Additionally, two

111 quantitative CT measures of emphysema and chronic bronchitis were obtained using CIRRUS

112 Lung Quantification (Diagnostic Image Analysis Group; Fraunhofer MEVIS): emphysema score

113 and bronchial wall thickness (Pi10) (26,27). Emphysema score was calculated by calculating the 
114 percentage of lung voxels below $-950 \mathrm{HU}$ after resampling the CT images to $3 \mathrm{~mm}$ slice

115 thickness, normalization, and bullae analysis $(28,29)$. Pi10 is the square root of the airway wall

116 area for a theoretical $10 \mathrm{~mm}$ lumen perimeter airway derived using the linear regression of the

117 square root of segmented wall area against the lumen perimeter (30).

118 Pulmonary nodules

119 The baseline and follow-up CT scans were screened for nodules by a trained medical researcher

120 with support from computer-aided detection software CIRRUS Lung Screening (Diagnostic

121 Image Analysis Group; Fraunhofer MEVIS). Only nodules of longest diameter of at least $3 \mathrm{~mm}$

122 were considered on the premise that the morphological features of smaller nodules would not be

123 perceptible. Size was extracted automatically from the nodule segmentation in the form of

124 volume, longest diameter, and short-axis diameter. Size changes in nodules which were detected

125 in both scans were recorded; if the difference was larger than the known measurement variance

126 of $\pm 22.3 \%$, the nodule was labelled as growing or shrinking (31).

127 In the baseline scans, all opacities deemed to be non-calcified nodules were subsequently

128 assessed independently by two radiologists: a general radiologist with over 30 years' experience

129 and a focus on chest radiology including 5 years of lung cancer screening experience, and a chest

130 radiologist with more than 20 years of experience in thoracic imaging. The classification options

131 were as follows: "PFN," "non-PFN solid," "part-solid," "non-solid," "calcified," and "not a

132 nodule." Disagreements were arbitrated by a third radiologist with over 30 years' experience.

133 All radiologists were familiar with the morphology of PFNs as described in the literature (19-

134 22). Non-calcified solid nodules with sharp margins and an oval or polygonal shape were eligible

135 as PFNs. Despite the nomenclature, PFNs do not need to be directly adjacent to fissures (20-22).

136 Readers were instructed to only classify a nodule as a PFN if highly certain that it was a lymph 
137 node. All opacities agreed on as "calcified" or "not a nodule" and opacities which were labelled

138 differently by all readers were excluded from the statistical analysis.

139 Statistical analysis

140 The observer study outcomes were imported into Microsoft Excel ${ }^{\mathrm{TM}} 365$ and subsequently $\mathrm{R}$

141 version statistical analysis package version 3.4.3. The number of PFNs, non-PFN solid, part-

142 solid and non-solid nodules was counted per scan. Nodule characteristics were compared

143 between PFNs and non-PFN solid nodules using the Mann-Whitney U test for continuous

144 variables and the chi-squared test for categorical variables. Inter-reader agreement was measured

145 using Cohen's kappa with all six nodule classification options and with two classes (PFN or not)

146 (32).

147 Regression analysis was performed to test whether the number and size (volume, longest

148 diameter, and short-axis diameter) of PFNs detected could predict COPD severity. Ordered

149 logistic regression (R function "polr" from package "MASS") was used to model ordinal

150 dependent variables (GOLD staging and $\mathrm{ABCD}$ assessment), and linear regression for

151 continuous variables (emphysema score and Pi10). This analysis was performed using four

152 outcome measures of COPD: GOLD severity groups ("Healthy" [GOLD 0 never and ever

153 smokers], "Mild" [GOLD 1 and 2 and PRISm], and "Moderate/severe" [GOLD 3 and 4]), ABCD

154 assessment, emphysema score $(\ln (x+1)$ transformed due to non-linearity of residuals), and Pi10.

155 PFN count was analysed as an independent variable at the subject level; PFN sizes were

156 modelled at the nodule level. This analysis was performed with and without adjustment for

157 the baseline variables age, sex (female VS male), race (non-Hispanic Black VS non-

158 Hispanic White), and smoking status (current VS former VS never). Smoking status was

159 not adjusted for when analysing GOLD severity groups because this variable was used to 
160 define the groups. Statistical significance was defined as $p<0.0253$ after applying the

161 Šidák correction for multiple comparisons (calculated for only two hypotheses because the

162 measures of PFN size and measures of COPD severity were considered complementary)

163 (33,34).The Shapiro-Wilk test was used to test for normality; all numeric outcomes were

164 not normally distributed $(\mathrm{p}<0.001)$ which justified performing the analyses using non-

165 parametric tests.

166 Post hoc analysis was performed using univariable linear regression to associate more

167 variables of interest - age, sex, race (White and non-Hispanic Black), educational level,

168 smoking status, smoking duration, exacerbation frequency, at least one severe

169 exacerbation, Modified Medical Research Council (mMRC) Dyspnea Scale, exposure to a

170 dusty job (for at least one year), and exposure to fumes at work (for at least one year) - to

171 PFN count and PFN volume. mMRC score and educational level was transformed into a

172 numeric trend; for the latter, 1 = "8th grade or less," 2 = "high school, no diploma," $3=$

173 "high school graduate or General Educational Development certificate," 4 = "some college

174 or technical school, no degree," 5 = “college or technical school graduate (Bachlor's or

175 Associate degree)," and 6= Master's or Doctoral degree." For these 22 comparisons, the

176 level of significance was lowered to 0.0023 (33).

177 Results

178 Observer study

179 The inclusion criteria and study design of COPDGene are described elsewhere (23). In short, it is

180 a multicenter observational study collecting clinical, functional, imaging, and genetic data related

181 to COPD. Ten thousand non-Hispanic Whites and Blacks between 45 and 80 years with and

182 without COPD were enrolled at baseline (between January 2008 and June 2011). All participants 
183 required at least 10 pack-years of smoking, except for the control group of 133 never-smokers. A

184 second screening round was performed five years after baseline.

185 The subject inclusion process is shown in Figure 1. Of the 350 subjects included, $26(7.4 \%)$ were

186 excluded because the baseline and/or follow-up scans were missing from the database. The

187 baseline characteristics across GOLD stages are shown in Table 1. Out of 324 baseline scans,

188592 nodules were included in the observer study; 211 scans $(65.1 \%)$ contained at least one

189 nodule. After the observer study had been performed independently by Readers A and B, there

190 were 163 disagreements (27.5\%) which were arbitrated by Reader C. After arbitration, six

191 opacities $(6 / 592,1.0 \%)$ were not considered nodules, five $(5 / 592,0.8 \%)$ were calcified, and six

$192(6 / 592,1.0 \%)$ were given different classifications by all three readers; these were excluded from

193 the statistical analysis. Fourteen subjects $(14 / 324,4 \%)$ had missing values for mMRC score

194 (therefore also lacking an ABCD assessment), 10 (3\%) had missing values for exposure to a

195 dusty job (for at least one year), and 20 (6\%) for exposure to fumes at work (for at least one

196 year); these were excluded from the relevant analyses.

\section{Inter-rater agreement}

198 Agreement in the form of Cohen's kappa between readers A and B for 592 nodules was 0.50

199 (95\% confidence interval: 0.43 to 0.56$)$ with six classification options and 0.54 (0.47 to 0.61$)$

200 when only distinguishing between a PFN and all other classification options, interpretable as

201 moderate agreement. Among the 163 disagreements, the six-class kappa between Readers A and

$202 \mathrm{C}$ and Readers B and C were 0.06 (-0.06 to 0.17$)$ and 0.17 (0.05 to 0.29$)$, respectively; the two-

203 class kappa were $0.11(-0.04$ to 0.26$)$ and 0.10 (-0.05 to 0.25$)$, respectively; these values signify

204 no significant agreement (32). 
206 The characteristics of the nodules analysed are summarized in Table 2. Most nodules were

207 classified as PFNs (366/575, 63.7\%); Figure 2 is an example of what is considered a typical

208 PFN. Compared to non-PFN solid nodules (180/575, 31.3\%), PFNs were more often smaller,

209 flatter in shape, found in the middle or lower lobes, and remained the same size at follow-up;

210 note that no nodule in the study was found to have a volume doubling time of less than 600 days.

211 A much smaller number of subsolid nodules $(29 / 575,5.0 \%)$ was detected.

\section{Perifissural nodule count}

213 The prevalence and distribution of PFNs across COPD GOLD groups are shown in Table 3 and

214 Figure 3, and the data is provided as a supplementary file which also includes basic

215 characteristics. Roughly one-third of the scans contained no nodules $(118 / 324,36.4 \%)$ and half

216 contained no PFNs (154/324, 47.5\%). The most PFNs found in one scan was 10 . The average

217 number of PFNs ranged from $0.92(1.50)$ in the GOLD 0 ever-smokers group to $1.40(1.95)$ in

218 the GOLD 4 group. PFN count was not a statistically significant predictor for GOLD severity

219 groups $(p=0.50), A B C D$ assessment $(p=0.94)$, emphysema score $(p=0.13)$, or Pi10 $(p=0.70)$.

220 The respective $\mathrm{p}$ values were $0.33,0.69,0.52$, and 0.94 after adjusting for other factors. There

221 were no significant associations of PFN count with other variables (Table 4), though there may

222 be a trend where non-Hispanic Blacks have fewer PFNs than Whites $(\mathrm{p}=0.005)$.

223 Perifissural nodule size

224 The distribution of PFN sizes across GOLD stages are listed in Table 3; Figure 4 shows a bar

225 plot of the PFN density (number of PFNs in the size category divided by the number of PFNs in

226 the GOLD stage) versus volume per GOLD stage. The median volume, longest diameter, and 
227 short-axis diameter of the PFNs analysed was $22.3 \mathrm{~mm}^{3}$ (interquartile range $=18 \mathrm{~mm}^{3}$ ), $4.8 \mathrm{~mm}$

$228(1.7 \mathrm{~mm})$, and $3.2 \mathrm{~mm}(1.0 \mathrm{~mm})$, respectively.

229 Volume, longest diameter, and short-axis diameter were larger on average in subjects higher

230 GOLD stages $(\mathrm{p}=0.050, \mathrm{p}=0.023$, and $\mathrm{p}=0.021$, respectively). The differences were largest

231 between the Mild and Moderate/severe groups; the difference between the Healthy and Mild

232 groups were not significant for longest diameter $(\mathrm{p}=0.51)$ and short-axis diameter $(\mathrm{p}=0.83)$.

233 Univariable analysis for ABCD assessment showed a stronger trend, where larger PFNs were

234 usually found in symptomatic participants at risk of exacerbation (volume $\mathrm{p}=0.002$; longest

235 diameter $\mathrm{p}=0.011$; short-axis $\mathrm{p}=0.012$ ). Only PFN volume was a significant predictor of

236 emphysema score $(p=0.043$; longest diameter $p=0.053$; volume $p=0.07$, respectively $)$. None

237 of the PFN sizes could be used as predictors of Pi10 $(p=0.14, p=0.19$, and $p=0.23$,

238 respectively).

239 After adjusting for other factors (excluding smoking status), only short-axis diameter remained a

240 statistically significant predictor of GOLD severity group $(\mathrm{p}=0.012$; volume $\mathrm{p}=0.050$; longest

241 diameter $\mathrm{p}=0.07)$. The respective $\mathrm{p}$ values for adjusted analysis of ABCD assessment are 0.076 ,

2420.017 , and 0.053 . However, excluding smoking status from the list of factors, the $\mathrm{p}$ values

243 dropped to values like in the univariable analyses (volume $\mathrm{p}=0.002$; longest diameter $\mathrm{p}=0.011$;

244 short-axis $\mathrm{p}=0.011$ ). The most statistically significant post hoc finding was the positive trend

245 between PFN volume and mMRC score $(\mathrm{p}=0.004)$, though the amount of variation explained

246 was 2\% (adjusted r-squared).

\section{Discussion}

248 The primary aim of this study was to determine whether a larger number or size of PFNs

249 detected in a CT scan was associated to a higher level of COPD severity. Four measures of 
250 COPD - one functional, one symptomatic, and two quantitative - were modelled. The reasoning

251 was that greater COPD severity is associated with more inflammation, which is associated with

252 an overactive immune system characterized by more enlarged intrapulmonary lymph nodes

253 identifiable on CT as PFNs. We found that PFN count did not differ across subjects with

254 different levels of COPD severity. However, there was a positive trend in PFN size for GOLD

255 severity and ABCD assessment groups, also when adjusted for age, sex, and race. The

256 differences in PFN sizes were less evident between the Healthy and Mild GOLD groups and the

257 B and C ABCD groups. Overall, the small group differences and the high variance prevent PFN

258 features from being clinically relevant measures: almost half (154/324, 47.5\%) of all scans

259 lacked a single PFN while the other half contained a range of one to 10 PFNs (Table 3).

260 The ABCD groups are determined based on the mMRC Dyspnea Scale and exacerbation

261 frequency and severity. In response to the positive findings related to ABCD assessment and

262 PFN size, these three variables were assessed to determine whether similar effects could be seen

263 in the individual components. Table 4 shows that dyspnea symptoms have a stronger association

264 with larger PFN volume $(p=0.004)$ than the measures of exacerbation risk $(p \geq 0.12)$. Other post

265 hoc analysis showed that there was a negative trend between the PFN count and non-Hispanic

266 Black race $(p=0.005)$, and that PFN volume was greater in current smokers compared to never-

267 smokers $(\mathrm{p}=0.058)$ and in those which had been exposed to a dusty work environment $(\mathrm{p}=$

268 0.043) (Table 4). However, considering the large number of comparisons, these may be false

269 positive findings (for which the significance level was set at 0.0023 ). Also, an association of

270 having 0.6527 fewer PFNs per scan is not clinically useful. No other trends were found between

271 PFN count or volume and other variables of interest. 
272 This is not the first study to investigate a relationship between the lymphatic system and COPD.

273 Brusselle and colleagues found a higher prevalence of peribronchial and parenchymal lymphoid

274 follicles in severe COPD cases (7), and Kirchner and colleagues found that about half of COPD

275 patients had enlarged mediastinal lymph nodes (8); they found no trend across increasing GOLD

276 stages. Notably, the literature defines enlarged mediastinal lymph nodes as those $10 \mathrm{~mm}$ or larger

277 in short-axis diameter $(8,9)$. Though the same threshold would not be useful for intrapulmonary

278 lymph nodes - only $1 \%$ of PFNs (4/366) fit this criterium - it is curious that our results also

279 found short-axis diameter to be better at distinguishing GOLD severity groups than volume and

280 longest diameter. One possible explanation would it is a better indicator of how "round" a PFN

281 is: a long but flat lymph node may be less active than a more swollen PFN. PFN volume may

282 also reflect this to a lesser extent.

283 Our findings agree with those of Mets and colleagues who investigated PFN malignancy chance

284 in a clinical setting (21). They found no significant differences in visually assessed presence or

285 extent of emphysema (4-point ordinal scale), presence of bronchial wall thickening, vascular

286 calcifications (4-point scale), or presence of hilar/mediastinal lymphadenopathy between patients

287 with and without PFNs. It was expected that bronchial wall thickness would have a greater

288 association to PFN count and size because it is a measure of bronchitis; it is unclear why a

289 stronger association was found between PFN size and GOLD stages - a measure of ventilation.

290 The PFN characteristics recorded (Table 2) are also comparable to those of previous studies (19-

291 22). Our results support the notion that the average PFN is significantly different from the

292 average non-PFN solid nodule. One of the few consistent criteria in defining a nodule as a PFN

293 is that it must be of solid consistency. Less consistent with previous reports is the relatively high

294 number of PFNs found in this study $(366 / 575,63.7 \%)$. As PFNs tend to be smaller, this may be 
295 explained by the inclusion of very small nodules in our study, though features are also more

296 difficult to distinguish among smaller nodules. However, 78 of the 575 nodules (13.6\%) were

297 marked with a comment on by at least one reader that it was too small to be certain that it was a

298 PFN; this indicates that the readers did not simply classify nodules as PFNs based on size or

299 benignity likelihood. Although such small nodules are clinically irrelevant when considering

300 malignancy probability, it could have been relevant for the purpose of this study. That half of the

301 PFNs grew or shrank in size has also been previously reported and does not influence its chance

302 of being a malignancy (20).

303 Variation in nodule detection rates between radiologists can be very high (34); this study largely

304 avoids this by preselecting nodules as well as relying on agreement among three independent

305 readers. The inter-radiologist agreement between the two readers who classified all nodules in

306 the observer study was 0.54 (95\% confidence interval: 0.47 to 0.61$)$ when distinguishing

307 between PFNs and any other classification; this is within the range reported by a previous study

308 on PFN reader variability among six readers (22). This indicates that some readers would

309 systematically detect more PFNs than other readers. On the other hand, our consensus reader had

310 a similar level of slight agreement (not statistically significant) with both initial readers, rejecting

311 the possibility of preferential treatment (despite blinding). No official PFN definition was

312 provided, which may have played a role in the observer variability and restricts reproducibility

313 for future studies.

314 There are several other limitations to our study. There is selection bias in that all subjects had a

315 baseline and follow-up scan, meaning that the subjects must have survived within the period of

316 five years in between. This was to ensure that nodule change could be recorded; it is unknown

317 whether the results would have differed without this selection criterium. 
318 No pathological confirmation was available to confirm which opacities were lymph nodes. Due

319 to the survival time and no nodule having a volume doubling time of less than 600 days, it can be

320 said with high certainty that cancers did not reside among them. Besides lymph nodes, many

321 solid nodules are expected to be granulomas which also originate in response to inflammation

322 but do not typically have the shape of lymph nodes on CT $(17,35)$. To account for the possibility

323 that the true number of intrapulmonary lymph nodes was greater than the number of PFNs

324 counted, the same analysis was performed on all solid nodules, but no significant trends were

325 found (results not included).

326 In conclusion, there was no association found between the number of PFNs detected in a chest

327 CT scan and the level of COPD severity. However, there may be a weak trend of larger

328 intrapulmonary lymph nodes in moderate to severe stages of COPD based on functional,

329 symptomatic, and quantitative CT measures. Nevertheless, it would likely not be a clinically

330 useful biomarker: Variance was large across subjects, where about half of the scans did not

331 contain any PFNs while as many as 10 PFNs were detected in one CT image. Additionally,

332 classifying nodules as PFNs without clear criteria was again shown to be a task with much

333 disagreement among experienced radiologists.

334

335 Acknowledgements

336 The COPDGene ${ }^{\circledR}$ project was supported by Award Number U01 HL089897 and Award Number

337 U01 HL089856 from the National Heart, Lung, and Blood Institute. The content is solely the

338 responsibility of the authors and does not necessarily represent the official views of the National

339 Heart, Lung, and Blood Institute or the National Institutes of Health. COPDGene ${ }^{\circledR}$ is also

340 supported by the COPD Foundation through contributions made to an Industry Advisory Board 
341 comprised of AstraZeneca, Boehringer Ingelheim, GlaxoSmithKline, Novartis, Pfizer, Siemens

342 and Sunovion.

\section{Declaration of interest}

344 The authors of this manuscript declare relationships with the following companies: Colin Jacobs

345 received a research grant from MeVis Medical Solutions AG; Mathias Prokop received research

346 funding from Toshiba, the speaker's bureau at Bracco, Bayer, Toshiba, and Siemens, and

347 performed a department spin-off at Thiroux (no personal financial interest); Bram van Ginneken

348 received royalties from MeVis Medical Solutions and Delft Imaging Systems, and is a co-

349 founder and shareholder of Thirona. David A Lynch received Grant support from the

350 NIH/NHLBI, and income as a consultant for Boehringer Ingelheim and Parexel. Anton

351 Schreuder, Ernst T Scholten, and Cornelia M Schaefer-Prokop do not have any competing 352 interests. 


\section{References}

354 1. Mathers CD, Loncar D. Projections of global mortality and burden of disease from 2002 to 355 2030. PLoS Med. 2006;3:e442.

356 2. World Health Organization (2017) Chronic obstructive pulmonary disease (COPD). World 357 Health Organization, Geneva. Available via

358 http://www.who.int/mediacentre/factsheets/fs315/en/. Accessed 08 August 2018.

359 3. Vestbo J. COPD: definition and phenotypes. Clin Chest Med. 2014;35(1):1-6.

360 4. Wan ES, Hokanson JE, Murphy JR, Regan EA, Make BJ, Lynch DA, Crapo JD, Silverman

361 EK; COPDGene Investigators. Clinical and radiographic predictors of GOLD-unclassified

362 smokers in the COPDGene study. Am J Respir Crit Care Med. 2011;184(1):57-63.

363 5. Noujeim C, Bou-Khalil P. COPD updates: what's new in pathophysiology and

364 management? Expert Rev Respir Med. 2013;7(4):429-437.

365 6. Habermann TM, Steensma DP. Lymphadenopathy. Mayo Clin Proc. 2000;75(7):723-732

366 7. Brusselle GG, Demoor T, Bracke KR, Brandsma C-A, Timens W. Lymphoid follicles in

367 (very) moderate/severe COPD: beneficial or harmful? Eur Respir J. 2009;34(1):219-230.

368 8. Kirchner J, Kirchner EM, Goltz JP, Obermann A, Kickuth R. Enlarged hilar and

369 mediastinal lymph nodes in chronic obstructive pulmonary disease. J Med Imaging Radiat

$370 \quad$ Oncol. 2010;54(4):333-338.

371 9. Nin CS, de Souza VV, do Amaral RH, Schuhmacher Neto R, Alves GR, Marchiori E, Irion 372 KL, Balbinot F, Meirelles GS, Santana P, Gomes AC, Hochhegger B. Thoracic 373 lymphadenopathy in benign diseases: a state of the art review. Respir Med. 2016;112:1017. 
375 10. Stump B, Cui Y, Kidambi P, Lamattina AM, El-Chemaly S. Lymphatic changes in

376 respiratory diseases: more than just remodeling of the lung? Am J Respir Cell Mol Biol.

$377 \quad 2017 ; 57(3): 272-279$.

378 11. Kradin RL, Spirn PW, Mark EJ. Intrapulmonary lymph nodes. Clinical, radiologic, and 379 pathologic features. Chest. 1985;87(5):662-667.

380 12. Bankoff MS, McEniff NJ, Bhadelia RA, Garcia-Moliner M, Daly BD. Prevalence of 381 pathologically proven intrapulmonary lymph nodes and their appearance on CT. AJR Am J $382 \quad$ Roentgenol. 1996;167(3):629-630.

383 13. Yokomise H, Mizuno H, Ike O, Wada H, Hitomi S, Itoh H. Importance of intrapulmonary 384 lymph nodes in the differential diagnosis of small pulmonary nodular shadows. Chest $385 \quad 1998 ; 113(3): 703-706$.

386 14. Miyake H, Yamada Y, Kawagoe T, Hori Y, Mori H, Yokoyama S. Intrapulmonary lymph 387 nodes: CT and pathological features. Clin Radiol. 1999;54(10):640-643.

388 15. Matsuki M, Noma S, Kuroda Y, Oida K, Shindo T, Kobashi Y. Thin-section CT features of 389 intrapulmonary lymph nodes. J Comput Tomogr. 2001;25(5):753-756.

390 16. Oshiro Y, Kusumoto M, Moriyama N, Kaneko M, Suzuki K, Asamura H, Kondo H, 391 Tsuchiya R, Murayama S. Intrapulmonary lymph nodes: thin-section CT features of 19 392 nodules. J Comput Assist Tomogr. 2002;26(4):553-557.

393 17. Hyodo T, Kanazawa S, Dendo S, Kobayashi K, Hayashi H, Kouno Y, Fujishima M, Hiraki 394 Y. Intrapulmonary lymph nodes: thin-section CT findings, pathological findings, and CT 395 differential diagnosis from pulmonary metastatic nodules. Acta Med Okayama. 2004;58(5):235-240. 
397 18. Wang CW, Teng YH, Huang CC, Wu YC, Chao YK, Wu CT. Intrapulmonary lymph

398 nodes: computed tomography findings with histopathologic correlations. Clin Imaging. $399 \quad 2013 ; 37(3): 487-492$.

400 19. Ahn MI, Gleeson TG, Chan IH, McWilliams AM, Macdonald SL, Lam S, Atkar-Khattra S, 401 Mayo JR. Perifissural nodules seen at CT screening for lung cancer. Radiology. $402 \quad 2010 ; 254(3): 949-956$.

403 20. Hoop B de, Ginneken B van, Gietema H, Prokop M. Pulmonary perifissural nodules on CT 404 scans: rapid growth is not a predictor of malignancy. Radiology. 2012;265:611-616.

405 21. Mets OM, Chung K, Scholten ET, Veldhuis WB, Prokop M, van Ginneken B, Schaefer406 Prokop CM, de Jong PA. Incidental perifissural nodules on routine chest computed 407 tomography: lung cancer or not? Eur Radiol. 2018;28:1095-1101.

408

22. Schreuder A, van Ginneken B, Scholten ET, Jacobs C, Prokop M, Sverzellati N, Desai SR, 409 Devaraj A, Schaefer-Prokop CM. Classification of CT pulmonary opacities as perifissural nodules: Reader Variability. Radiology. 2018;288(3):867-875.

411 23. Regan EA, Hokanson JE, Murphy JR, Make B, Lynch DA, Beaty TH, Curran-Everett D,

412 Silverman EK, Crapo JD. Genetic epidemiology of COPD (COPDGene) study design. $413 \quad$ COPD. 2010;7:32-43.

414 24. Fritz CO, Morris PE, Richler JJ. Effect size estimates: current use, calculations, and 415 interpretation. J Exp Psychol. 2012;141(1):2-18.

41625 Singh D, Agusti A, Anzueto A, Barnes PJ, Bourbeau J, Celli BR, Criner GJ, Frith P, 417 Halpin DMG, Han M, López Varela MV, Martinez F, Montes de Oca M, Papi A, Pavord 418 ID, Roche N, Sin DD, Stockley R, Vestbo J, Wedzicha JA, Vogelmeier C. Global Strategy 
419 for the Diagnosis, Management, and Prevention of Chronic Obstructive Lung Disease: the 420 GOLD science committee report 2019. Eur Respir J. 2019;53(5). pii:1900164.

421 26. Gallardo-Estrella L, Pompe E, de Jong PA, Jacobs C, van Rikxoort EM, Prokop M, 422 Sánchez CI, van Ginneken B. Normalized emphysema scores on low dose CT: Validation 423 as an imaging biomarker for mortality. PLoS One. 2017;12(12):e0188902.

424 27. Kim V, Davey A, Comellas AP, Han MK, Washko G, Martinez CH, Lynch D, Lee JH, 425 Silverman EK, Crapo JD, Make BJ, Criner GJ; COPDGene® Investigators. Clinical and 426 computed tomographic predictors of chronic bronchitis in COPD: a cross sectional analysis 427 of the COPDGene study. Respir Res 2014;15:52.

428 28. Gevenois PA, De Vuyst P, de Maertelaer V, Zanen J, Jacobovitz D, Cosio MG, Yernault 429 JC. Comparison of computed density and microscopic morphometry in pulmonary emphysema. Am J Respir Crit Care Med. 1996;154(1):187-192.

29. Gallardo-Estrella L, Lynch DA, Prokop M, Stinson D, Zach J, Judy PF, van Ginneken B, 432 van Rikxoort EM. Normalizing computed tomography data reconstructed with different filter kernels: effect on emphysema quantification. Eur Radiol. 2016;26:478-486.

30. Charbonnier JP, Pompe E, Moore C, Humphries S, van Ginneken B, Make B, Regan E, Crapo JD, van Rikxoort EM, Lynch DA; COPDGene investigators. Airway wall thickening on CT: relation to smoking status and severity of COPD. Respir Med. 2019;146:36-41.

437 31. Hoop B de, Gietema H, Ginneken B van, Zanen P, Groenewegen G, Prokop M. A comparison of six software packages for evaluation of solid lung nodules using semiautomated volumetry: what is the minimum increase in size to detect growth in repeated CT examinations. Eur Radiol. 2009;19:800-808. 
441 32. Cohen J. A coefficient of agreement for nominal scales. Educ Psychol Meas.

$442 \quad 1960 ; 20(1): 37-46$.

443 33. Šidák ZK. Rectangular confidence regions for the means of multivariate normal

444 distributions. J Am Stat Assoc. 1967;62(318):626-633.

445 34. Rothman KJ. No adjustments are needed for multiple comparisons. Epidemiology.

$446 \quad 1990 ; 1: 43-46$.

447 35. Honma K, Nelson G, Murray J. Intrapulmonary lymph nodes in South African miners-an $448 \quad$ autopsy survey. Am J Ind Med. 2007;50(4):261-264.

449 
Figure 1

Subject selection process

Abbreviations: PRISm, preserved ratio impaired spirometry. 
COPDGene subjects available, $n=10000$
Baseline and follow-up CT available $(n=4928,49.3 \%)$ :

-Never-smokers, $\mathrm{n}=66$

-GOLD 0, n=2228

-PRISm, n=577

-GOLD 1, n=437

-GOLD 2, n=948

-GOLD 3, n=522

-GOLD 4, n=150
Subjects selected at

random $(n=350,7.1 \%)$ :

Never-smokers, $n=50,75.8 \%$

GOLD $0, n=50,2.2 \%$

PRISm, $n=50,8.7 \%$

GOLD 1, $\mathrm{n}=50,11.4 \%$

GOLD 2, $\mathrm{n}=50,9.3 \%$

GOLD 3, $n=50,9.6 \%$

GOLD 4, n=50, 33.3\%

Subjects included

$(n=324,92.6 \%)$ :

Never-smokers, $n=49,98 \%$

GOLD 0, $\mathrm{n}=50,100 \%$

PRISm, $n=43,86 \%$

GOLD 1, $n=47,94 \%$

GOLD 2, $n=45,90 \%$

GOLD 3, $n=45,90 \%$

GOLD 4, n=45, 90\%
Missing CT scans $(\mathrm{n}=26$, $7.4 \%$ ):

Never-smokers, $n=1,2 \%$ PRISm, $n=7,14 \%$

GOLD 1, $n=3,6 \%$

GOLD 2, $n=5,10 \%$

GOLD 3, $n=5,10 \%$

GOLD 4, n=5, 10\%

Opacities $\geq 9 \mathrm{~mm}^{3}$ annotated and included in the observer study,

$\mathrm{n}=592$ in 211 scans

Scans with no nodules, $\mathrm{n}=113 / 324(34.9 \%)$ 


\section{Figure 2}

CT image of a typical perifissural nodule attached to a fissure

The nodule is a well-defined non-calcified solid nodule which is triangular in shape with a flattened side adjacent to a pulmonary fissure.

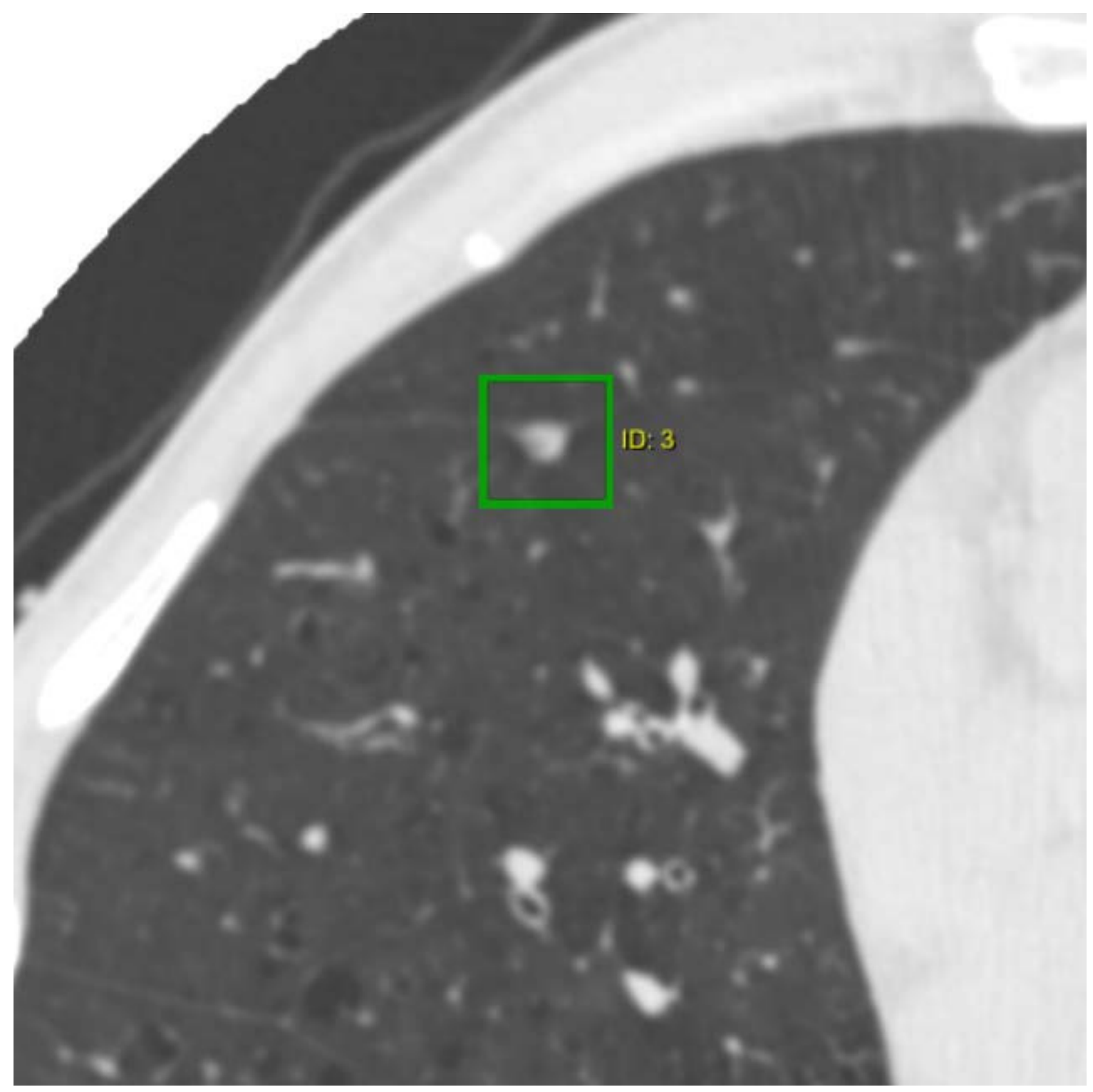




\section{Figure 3}

\section{Distribution of PFNs across COPD GOLD stages}

A 100\% stacked bar chart illustrating the number of PFNs distributed across scans within each GOLD group. The line represents the average number of PFNs per scan for each group (given on the right axis). Abbreviations: ES, ever-smoker; NS, never-smoker; PFN, perifissural nodule; PRISm, preserved ratio impaired spirometry.

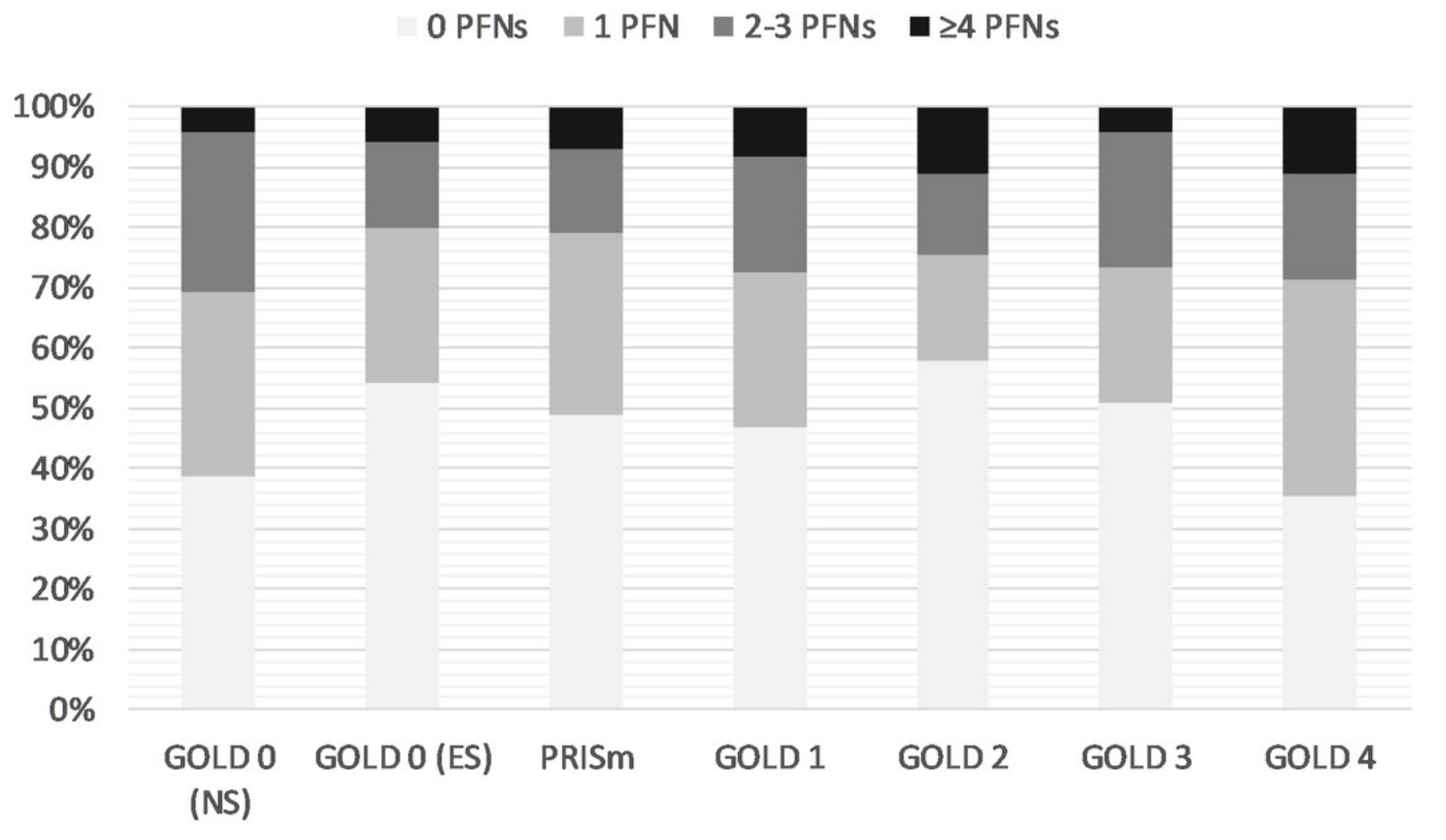




\section{Figure 4}

Density of perifissural nodules across short-axis diameters and GOLD stages

A bar chart of the density (number of PFNs in the size category divided by the number of PFNs in the GOLD stage) of perifissural nodules grouped by volume and GOLD stage. The association between GOLD severity groups (Healthy: GOLD 0 never- and ever-smokers; Mild: PRISm and GOLD 1 and 2; Moderate/severe: GOLD 3 and 4) was not considered statistically significant with $(p=0.050)$ and without adjusting for other factors $(p=0.050)$. Abbreviations: PFN, perifissural nodule; PRISm, preserved ratio impaired spirometry.

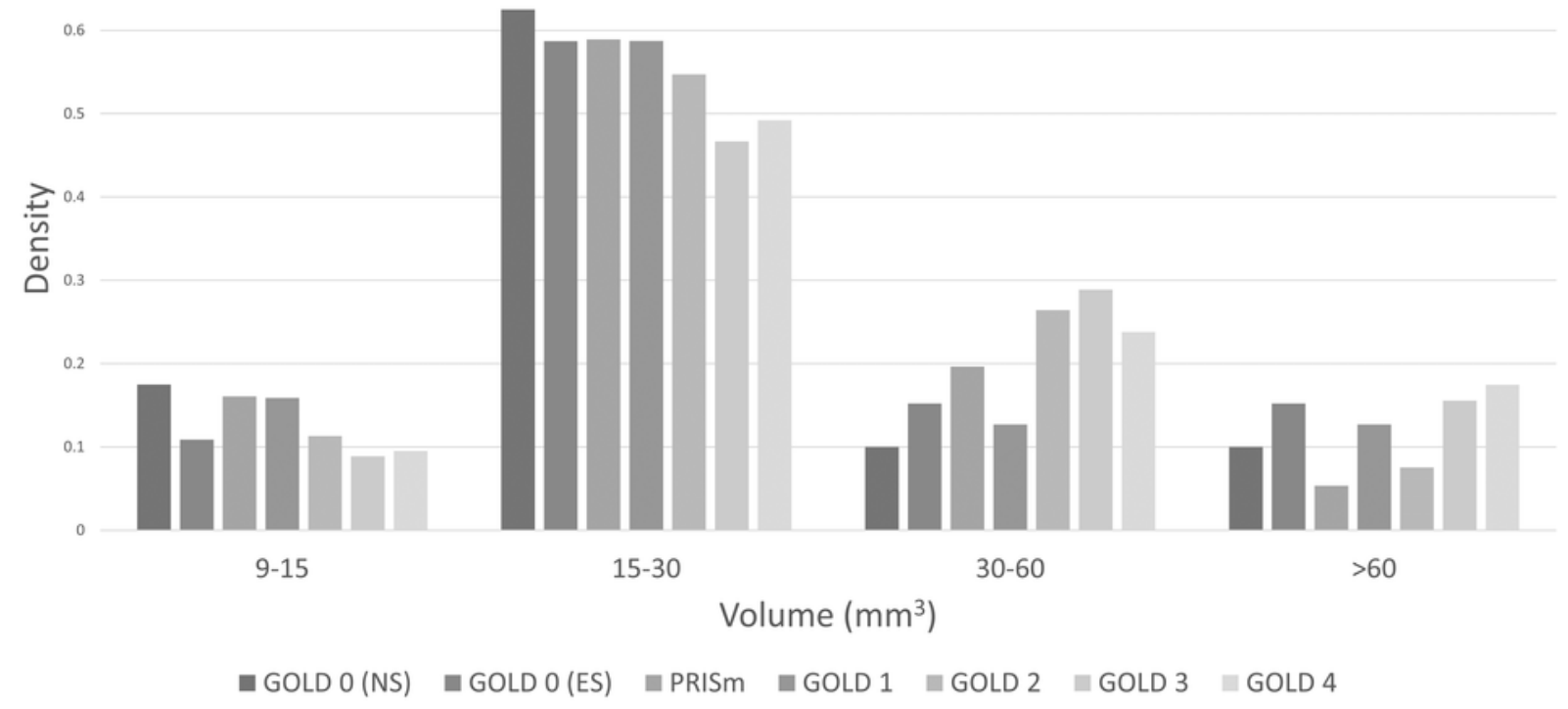




\section{Table $\mathbf{1}$ (on next page)}

Baseline subject descriptive statistics

For emphysema score, the values given are medians followed by the $25^{\text {th }}$ and $75^{\text {th }}$ percentiles in parentheses. The remaining continuous variables are given as means followed by the standard deviations in parentheses. The $p$ values of all continuous variables were calculated using the linear regression $F$ test. For factors, values in parentheses are percentages; the $p$ values were calculated from the chi-square test. Abbreviations: ES, ever-smoker; NS, neversmoker; Pi10, bronchial wall thickness; PRISm, preserved ratio impaired spirometry. 


\begin{tabular}{|c|c|c|c|c|c|c|c|c|c|}
\hline GOLD stage & 0 (NS), n=49 & $0(E S), n=50$ & PRISm, $n=43$ & $1, n=47$ & $2, n=45$ & $3, n=45$ & $4, n=45$ & $P$ value & $\begin{array}{l}\text { Total, } \\
\mathrm{n}=324\end{array}$ \\
\hline Age (years) & $64.3(9.6)$ & $63.9(8.7)$ & $60.9(7.5)$ & $67.9(8.2)$ & $68.3(7.5)$ & $68.5(8.5)$ & $66.9(8.0)$ & $<0.001$ & $65.8(8.7)$ \\
\hline Sex (female) & $32(9.9)$ & $30(9.3)$ & $19(5.9)$ & $24(7.4)$ & $20(6.2)$ & $16(4.9)$ & $16(4.9)$ & 0.021 & $157(48.5)$ \\
\hline $\begin{array}{l}\text { Race (non- } \\
\text { Hispanic Black) }\end{array}$ & $4(1.2)$ & $9(2.8)$ & $20(6.2)$ & $8(2.5)$ & $9(2.8)$ & $10(3.1)$ & $7(2.2)$ & 0.001 & $67(20.7)$ \\
\hline Smoking status & & & & & & & & $<0.001$ & \\
\hline Current & $0(0)$ & $19(5.9)$ & $21(6.5)$ & $15(4.6)$ & $17(5.2)$ & $9(2.8)$ & $3(0.9)$ & & $84(25.9)$ \\
\hline Former & $0(0)$ & $31(9.6)$ & $22(6.8)$ & $32(9.9)$ & $28(8.6)$ & $36(11.1)$ & $42(13)$ & & $191(59)$ \\
\hline Never & $49(15.1)$ & $0(0)$ & $0(0)$ & $0(0)$ & $0(0)$ & $0(0)$ & $0(0)$ & & $49(15.1)$ \\
\hline Emphysema score & $0.1(0.0-0.1)$ & $0.1(0.0-0.2)$ & $0.0(0.00-0.1)$ & $0.6(0.1-3.5)$ & $0.5(0.1-2.1)$ & $3.9(0.2-14.4)$ & $\begin{array}{l}15.2(4.2- \\
31.2)\end{array}$ & $<0.001$ & $4.6(9.5)$ \\
\hline Pi10 & $1.73(0.29)$ & $2.01(0.49)$ & $2.57(0.53)$ & $2.07(0.51)$ & $2.67(0.52)$ & $2.96(0.62)$ & $2.88(0.45)$ & $<0.001$ & $\begin{array}{l}2.39 \\
(0.66)\end{array}$ \\
\hline ABCD assessment & & & & & & & & $<0.001$ & \\
\hline$A$ & $48(15.5)$ & $38(12.3)$ & $21(6.8)$ & $34(11.0)$ & $21(6.8)$ & $12(3.9)$ & $1(0.3)$ & & $175(54.0)$ \\
\hline $\boldsymbol{B}$ & $0(0)$ & $9(2.9)$ & $14(4.5)$ & $8(2.6)$ & $15(4.8)$ & $16(5.2)$ & $19(6.1)$ & & $81(25.0)$ \\
\hline C & $0(0)$ & $2(0.6)$ & $4(1.3)$ & $3(1.0)$ & $1(0.3)$ & $1(0.3)$ & $0(0)$ & & $11(3.4)$ \\
\hline$D$ & $0(0)$ & $1(0.3)$ & $4(1.3)$ & $2(0.6)$ & $8(2.6)$ & $16(5.2)$ & $12(3.9)$ & & $43(13.3)$ \\
\hline
\end{tabular}




\section{Table 2 (on next page)}

Nodule characteristics

For continuous variables, the values given are medians followed by the $25^{\text {th }}$ and $75^{\text {th }}$ percentiles in parentheses and the $p$ values were calculated from the Mann-Whitney $U$ test. For factors, values in parentheses are percentages and the $p$ values were calculated from the chi-squared test. The statistical tests were only performed comparing the "PFN" to the "nonPFN solid" groups. Abbreviations: PFN, perifissural nodule. 


\begin{tabular}{|c|c|c|c|c|c|}
\hline Characteristic & PFN, $n=366$ & $\begin{array}{l}\text { Non-PFN solid, } \\
n=180\end{array}$ & $\begin{array}{l}\mathbf{P} \\
\text { value }\end{array}$ & Part-solid, $n=2$ & $\begin{array}{l}\text { Non-solid, } \\
\mathbf{n}=27\end{array}$ \\
\hline Volume $\left(\mathrm{mm}^{3}\right)$ & $22(17$ to 35$)$ & $32(18$ to 80$)$ & $<0.001$ & $\begin{array}{l}3594(1836 \text { to } \\
5351)\end{array}$ & $92(55$ to 220$)$ \\
\hline Longest diameter (mm) & $\begin{array}{l}4.8(4.0 \text { to } \\
5.7)\end{array}$ & $4.9(4.0$ to 6.8$)$ & 0.17 & $19.1(12.8$ to 25.5$)$ & $\begin{array}{l}6.3(5.6 \text { to } \\
10.3)\end{array}$ \\
\hline $\begin{array}{l}\text { Short-axis diameter } \\
(\mathrm{mm})\end{array}$ & $\begin{array}{l}3.2(2.7 \text { to } \\
3.7)\end{array}$ & $3.6(3.0$ to 4.7$)$ & $<0.001$ & $10.3(7.8$ to 12.8$)$ & $4.6(3.7$ to 6.8$)$ \\
\hline Lobe location & & & 0.001 & & \\
\hline Right upper & $63(17.2)$ & $35(19.4)$ & & $1(50.0)$ & $12(44.4)$ \\
\hline Right middle & 57 (15.6) & $8(4.4)$ & & $0(0.0)$ & $1(3.7)$ \\
\hline Right lower & $91(24.9)$ & $45(25.0)$ & & $0(0.0)$ & $6(22.2)$ \\
\hline Left upper & $66(18.0)$ & $50(27.8)$ & & $0(0.0)$ & $6(22.2)$ \\
\hline Left lower & $89(24.3)$ & $42(23.3)$ & & $1(50.0)$ & $2(7.4)$ \\
\hline Change & & & $<0.001$ & & \\
\hline Regression & $115(31.4)$ & $98(54.4)$ & & $0(0)$ & $7(25.9)$ \\
\hline Stable & $175(47.8)$ & $56(31.1)$ & & $1(50.0)$ & $8(29.6)$ \\
\hline Growth & $76(20.8)$ & $26(14.4)$ & & $1(50.0)$ & $12(44.4)$ \\
\hline
\end{tabular}




\section{Table 3 (on next page)}

Prevalence of nodules and perifissural nodules across COPD GOLD stages

The original GOLD groups were combined to form the "Healthy" (GOLD 0 never- and eversmokers), "Mild" (PRISm and GOLD 1 and 2), and "Moderate/severe" (GOLD 3 and 4) groups. The number of scans and PFNs are given in frequency and percentages. The number of PFNs per scan is given in means and standard deviations. The measures of size are given in medians and $25^{\text {th }}$ and $75^{\text {th }}$ percentiles. Ordered logistic regression between the Healthy, Mild, and Moderate/severe groups was performed to analyze whether the number or size of PFNs could predict COPD severity. Abbreviations: no., number of; ES, ever-smoker; NS, neversmoker; PFN, perifissural nodule; PRISm, preserved ratio impaired spirometry. 


\begin{tabular}{|c|c|c|c|c|c|c|}
\hline COPD severity & $\begin{array}{l}\text { No. baseline } \\
\text { scans }\end{array}$ & $\begin{array}{l}\text { No. } \\
\text { PFNs }\end{array}$ & $\begin{array}{l}\text { No. PFNs } \\
\text { per scan }\end{array}$ & $\begin{array}{l}\text { PFN } \\
\text { volume } \\
\left(\mathrm{mm}^{3}\right)\end{array}$ & $\begin{array}{l}\text { PFN longest } \\
\text { diameter }(\mathrm{mm})\end{array}$ & $\begin{array}{l}\text { PFN short-axis } \\
\text { diameter }(\mathrm{mm})\end{array}$ \\
\hline Healthy & $99(31)$ & $\begin{array}{l}102 \\
(28)\end{array}$ & $\begin{array}{l}1.03 \\
(1.37)\end{array}$ & $\begin{array}{l}21(16 \text { to } \\
33)\end{array}$ & 4.6 (3.9 to 5.3$)$ & $\begin{array}{l}3.2(2.6 \text { to } \\
3.6)\end{array}$ \\
\hline GOLD 0 (NS) & $49(15)$ & $56(15)$ & $1.14(1.24)$ & $20(16$ to 29$)$ & $4.5(3.9$ to 5.2$)$ & $3.0(2.6$ to 3.4$)$ \\
\hline GOLD 0 (ES) & $50(15)$ & $46(13)$ & $0.92(1.50)$ & $\begin{array}{l}22.2(17.0 \text { to } \\
39.8)\end{array}$ & $4.0(4.8$ to 5.4$)$ & $3.2(2.4$ to 3.8$)$ \\
\hline Mild & $135(42)$ & $\begin{array}{l}156 \\
(43)\end{array}$ & $\begin{array}{l}1.16 \\
(1.89)\end{array}$ & $\begin{array}{l}22(17 \text { to } \\
32)\end{array}$ & $5.0(4.1$ to 5.8$)$ & $\begin{array}{l}3.1(2.7 \text { to } \\
3.8)\end{array}$ \\
\hline PRISm & $43(13)$ & $40(11)$ & $0.93(1.39)$ & $18(17$ to 27$)$ & $5.0(4.3$ to 5.9$)$ & $3.1(2.7$ to 4.0$)$ \\
\hline GOLD 1 & $47(15)$ & $63(17)$ & $1.34(2.08)$ & $21(16$ to 31$)$ & 4.7 (3.9 to 5.7$)$ & $2.9(2.7$ to 3.4$)$ \\
\hline GOLD 2 & $45(14)$ & $53(14)$ & $1.18(2.10)$ & 25 (18 to 38$)$ & $5.1(4.1$ to 5.8$)$ & $3.4(2.9$ to 3.9$)$ \\
\hline $\begin{array}{l}\text { Moderatel } \\
\text { severe }\end{array}$ & $90(28)$ & 108 & $\begin{array}{l}1.20 \\
(1.70)\end{array}$ & $\begin{array}{l}26(18 \text { to } \\
47)\end{array}$ & $5.0(4.2$ to 5.9$)$ & $\begin{array}{l}3.3(2.8 \text { to } \\
3.9)\end{array}$ \\
\hline GOLD 3 & $45(14)$ & $45(12)$ & $1.00(1.40)$ & $27(18$ to 48$)$ & $5.0(4.2$ to 5.5$)$ & $3.4(3.0$ to 3.9$)$ \\
\hline GOLD 4 & $45(14)$ & $63(17)$ & $1.40(1.95)$ & $26(17$ to 46$)$ & $5.0(3.9$ to 6.0$)$ & $3.2(2.7$ to 3.8$)$ \\
\hline Total & $324(100)$ & $\begin{array}{r}366 \\
(100)\end{array}$ & $\begin{array}{l}1.13 \\
(1.69)\end{array}$ & $\begin{array}{l}22(17 \text { to } \\
35)\end{array}$ & $\begin{array}{l}4.8(4.0 \text { to } \\
5.7)\end{array}$ & $\begin{array}{l}3.2(2.7 \text { to } \\
3.7)\end{array}$ \\
\hline$P$ value & - & - & 0.50 & 0.07 & 0.07 & 0.07 \\
\hline
\end{tabular}




\section{Table 4 (on next page)}

Perifissural nodule count and volume association with other variables

Univariable linear regression between the number and volume of PFNs and other variables of interest. The $\beta$ coefficient represents the magnitude of the association. mMRC score and educational level was transformed into a numeric variable (for the latter, $1=$ "8th grade or less," 2 = "high school, no diploma," 3 = "high school graduate or General Educational Development certificate," 4 = "some college or technical school, no degree," 5 = "college or technical school graduate," and $6=$ Master's or Doctoral degree."). Emphysema score was $\ln (x+1)$ transformed. A $p$ value of less than 0.0023 was considered significant. Abbreviations: mMRC, Modified Medical Research Council; no., number of; PFN, perifissural nodule; Ref., reference variable. 


\begin{tabular}{|c|c|c|c|c|}
\hline \multirow[t]{2}{*}{ Variable } & \multicolumn{2}{|c|}{ No. PFNs per scan } & \multicolumn{2}{|c|}{ PFN volume $\left(\mathbf{m m}^{3}\right)$} \\
\hline & $\beta$ coefficient & $\mathrm{P}$ value & $\beta$ coefficient & P value \\
\hline Age (years) & 0.02005 & 0.06 & -0.2286 & 0.19 \\
\hline Sex (female) & 0.1563 & 0.41 & -1.871 & 0.55 \\
\hline Race (non-Hispanic Black) & -0.6527 & 0.005 & 6.889 & 0.16 \\
\hline Educational level (per unit) & -0.03459 & 0.65 & -1.347 & 0.29 \\
\hline Smoking status & & 0.21 & & 0.11 \\
\hline Current & Ref. & Ref. & Ref. & Ref. \\
\hline Former & 0.3889 & 0.08 & -1.459 & 0.71 \\
\hline Never & 0.2857 & 0.35 & -10.042 & 0.058 \\
\hline Smoking duration (years) & 0.004093 & 0.40 & 0.03057 & 0.69 \\
\hline Exacerbation frequency (count) & 0.05789 & 0.54 & 2.129 & 0.12 \\
\hline At least one severe exacerbation & 0.3229 & 0.28 & 1.125 & 0.80 \\
\hline mMRC score (per unit) & -0.03202 & 0.65 & 3.064 & 0.004 \\
\hline Exposure to dusty job & -0.1439 & 0.46 & 6.485 & 0.043 \\
\hline Exposure to fumes at work & -0.02020 & 0.92 & 4.170 & 0.18 \\
\hline Emphysema score (per unit) & 0.1237 & 0.13 & 2.631 & 0.043 \\
\hline Pi10 (per unit) & -0.05412 & 0.70 & 0.2291 & 0.14 \\
\hline $\mathrm{ABCD}$ assessment (ordered $\mathrm{A}$ to $\mathrm{D})$ & -0.004985 & 0.94 & 0.1017 & 0.002 \\
\hline
\end{tabular}

